ISSN 2075-1702

www.mdpi.com/journal/machines/

Article

\title{
Contactless Mechanical Components: Gears, Torque Limiters and Bearings
}

\author{
Jose Luis Perez-Diaz ${ }^{1, \dagger}$, Efren Diez-Jimenez ${ }^{2, \dagger, *}$, Ignacio Valiente-Blanco ${ }^{3, \dagger}$, \\ Cristian Cristache ${ }^{4, \dagger}$, Marco-Antonio Alvarez-Valenzuela ${ }^{2, \dagger}$ \\ and Juan Sanchez-Garcia-Casarrubios $3, \uparrow$
}

1 Departamento de Teoría de la Señal y Comunicaciones, Universidad de Alcalá, 28871,

Alcalá de Henares, Spain; E-Mail: jl.perezd@uah.es

2 Departamento de Ingeniería Mecánica, Universidad Carlos III de Madrid, 28911, Leganés, Spain;

E-Mail: maavalen@ing.uc3m.es

3 R\&D department, MAG SOAR SL, 28341, Valdemoro, Spain;

E-Mails: ivaliente@magsoar.com (I.V.-B.); jsanchez@magsoar.com (J.S.-G.-C.)

4 Instituto Pedro Juan de Lastanosa, Universidad Carlos III de Madrid, 28911, Leganés, Spain;

E-Mail: ccristac@di.uc3m.es

$\dagger$ All the authors contributed equally to this work.

* Author to whom correspondence should be addressed: E-Mail: ediez@ ing.uc3m.es;

Tel.: +34-916-249-912.

External Editor: David Mba

Received: 2 October 2014; in revised form: 20 November 2014 / Accepted: 8 December 2014 /

Published: 18 December 2014

Abstract: Contactless mechanical components are mechanical sets for conversion of torque/speed, whose gears and moving parts do not touch each other, but rather they provide movement with magnets and magnetic materials that exert force from a certain distance. Magneto-mechanical transmission devices have several advantages over conventional mechanisms: no friction between rotatory elements (no power losses or heat generation by friction so increase of efficiency), no lubrication is needed (oil-free mechanisms and no lubrication auxiliary systems), reduced maintenance (no lubricant so no need of oil replacements), wider operational temperature ranges (no lubricant evaporation or freezing), overload protection (if overload occurs magnet simply slides but no teeth brake), through-wall connection (decoupling of thermal and electrical paths and 
environmental isolation), larger operative speeds (more efficient operative conditions), ultralow noise and vibrations (no contact no noise generation). All these advantages permit us to foresee in the long term several common industrial applications in which including contactless technology would mean a significant breakthrough for their performance. In this work, we present three configurations of contactless mechanical passive components: magnetic gears, magnetic torque limiters and superconducting magnetic bearings. We summarize the main characteristic and range of applications for each type; we show experimental results of the most recent developments showing their performance.

Keywords: contactless mechanical component magnetic gear; magnetic torque limiter; superconducting magnetic bearing

\section{Introduction}

Contactless mechanical components are mechanical sets for the conversion of torque/speed, whose gears and moving parts do not touch each other, but rather they provide movement with magnets and magnetic materials that exert force from a certain distance without any kind of contact between moving parts. Magneto-mechanical transmission devices have several advantages over conventional mechanisms: lack of wear, silent operation, reduced vibration, no need of lubrication, overload protection, reduced maintenance and improved reliability.

Furthermore, they are able to work in cryogenic environments, requirement which is more and more demanded for the new space telescopes and astronomical instruments because the lower the temperature, the better the sensitivity of some new sensors. At very low temperatures, conventional mechanisms present tribological problems in bearings and joints like backlash, cold spots, fatigue and wear [1,2]. Only solid lubricants such as PFTE or MoS2 can be a solution at low temperatures [3]. However, for long life-time operation solid lubricants turn out not to be a very reliable solution. Contactless mechanical components may represent the optimal solution to aerospace, space and mechanical engineering industry where lifetime and reliability are a key factor. In this way, governments and companies are investing in the research and development of such a kind of mechanical devices. The specific development of magnetic gears for aerospace has been the objective of several projects carried out in MAG SOAR facilities; some of them funded by the European Community's SPACE and CLEAN SKY Programs.

In this work, we present three types of contactless mechanical components: magnetic gears, magnetic torque limiters and superconducting magnetic bearings. All of these components are completely passive; therefore, external mechanical power supply is always needed. In this work, we state the main characteristic and range of applications for each type; we show experimental results of the most recent developments using both models and prototypes comparing their performance to commercial conventional mechanical systems. 


\section{Magnetic Gears}

Magnetic gears were proposed almost a hundred years ago. The absence of contact and wear between teeth seemed a worthy feature to prompt their development, but low magnetic product, difficulties with manufacturing techniques and cost were strong handicaps. At the beginning of this century, attention was paid to their development, using new magnetic materials with higher magnetization or permeability, new precise manufacturing techniques and advanced magneto-mechanical modeling tools. The number of papers devoted to magnetic gears has increased exponentially in the last two years and the technology has overcome many of the first difficulties [4,5].

The specific development of magnetic gears for aerospace has been the objective of several projects carried out in MAG SOAR facilities; some of them funded by the European Community's SPACE and CLEAN SKY Programs ([FP7/2007-2013]) [6-8].

The main advantages of magnetic gears are a consequence of the absence of contact between teeth. There is no wear. No lubricant is needed. They can be operated at a broad range of temperature ranging from $-270{ }^{\circ} \mathrm{C}$ up to $350{ }^{\circ} \mathrm{C}$ depending on the kind of bearings they mount. They present intrinsic antijamming properties and there is a clutching effect if the applied torque overpasses a limit therefore protecting the output from overloads. This effect is completely reversible. No damage or wear is produced while operating. The motion direction is also reversible with highly reduced backlash. Input and output axles can also be exchanged so that the same device can be used as a reducer or a multiplier. An additional advantage is that they are suitable for through-wall transmission requiring no joints or sealing. Magnetic gears are also compatible with the presence of dust, sand or non-magnetic particles. As there is a gap between the moving parts, sand can flow not producing significant scratches, wear or stalling.

Magnetic gears can be designed in configurations similar to conventional gears: mainly spur gears, planetary gears and "harmonic drives".

\subsection{Spur Gears and Planetary Gears}

Direct spur gears consist of a pinion and wheel set with permanent magnets alternating their poles able to magnetically engage. These poles are equivalent to the teeth in conventional gears. The characteristics of this sort of gears are greatly dependent on size, shape, materials and geometry. As in conventional spur gears only moderated ratios can be achieved. Although useful for some applications, spur gears are worth to be combined in planetary configurations to achieve high ratios with relatively low mass and volume. Figure 1 shows two examples of spur gear and planetary gear configuration.

Table 1 shows the performance of a magnetic planetary gear. The data shown for the planetary gear correspond to a general configuration not yet optimized. An optimization of parameters with a defined objective can typically improve greatly any of the characteristics.

The torque density of the magnetic planetary gear is smaller than the purely mechanical one (planetary gear from HD company Size 14 has $65 \mathrm{kNm} / \mathrm{m}^{3}$ [9]) despite the fact that the maximum torque, reduction ratio and maximum speeds are similar. Efficiency is expected to be greater due to the lack of losses in the teeth contact. Temperature operational ranges are larger because there is no need to lubricate the teeth contact; however, it will always depend on the bearing selection. 
Figure 1. (Left) 1:2 Magnetic Spur Gear, maximum torque: $24.2 \mathrm{Nm}$. (Right) 1:5 Magnetic Spur Gear, maximum torque: $32 \mathrm{Nm}$.

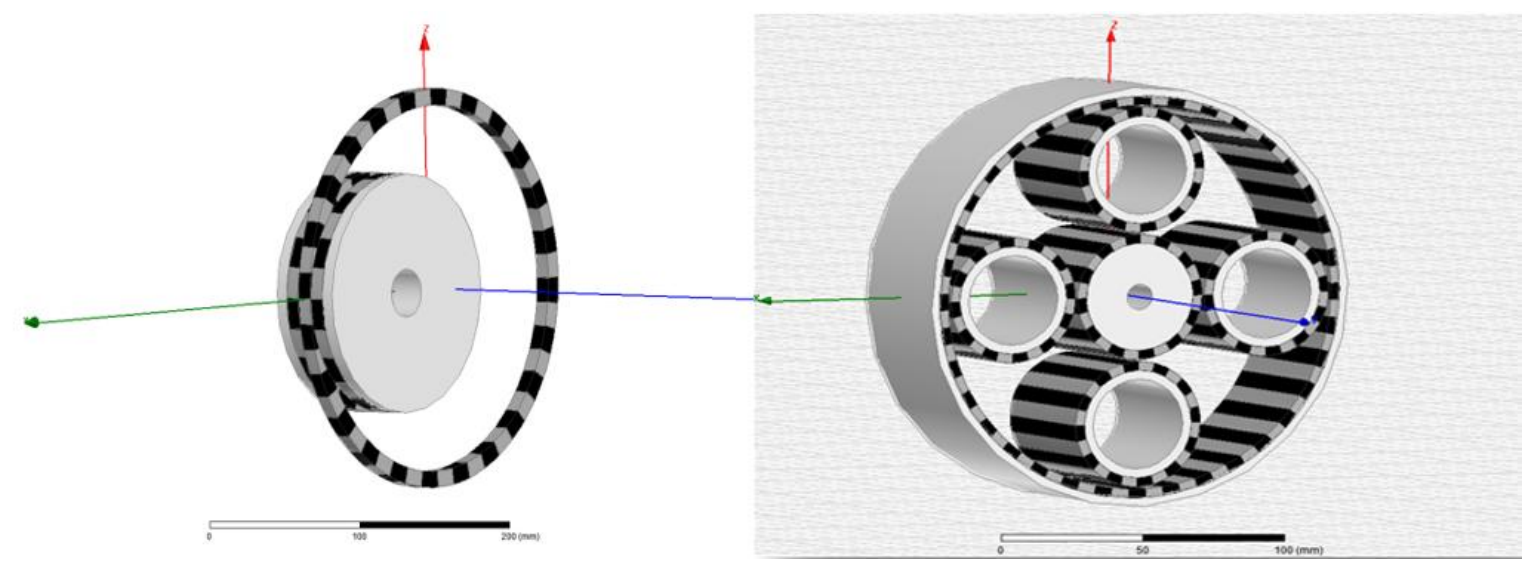

Table 1. Performances of a magnetic planetary gear.

\begin{tabular}{cc}
\hline Specification & $\begin{array}{c}\text { Magnetic } \\
\text { Planetary Gear }\end{array}$ \\
\hline Reduction ratio (i) & 4 \\
Max output torque $(\mathrm{Nm})$ & 26 \\
Torque Density $\left(\mathrm{kNm} / \mathrm{m}^{3}\right)$ & 24 \\
Max input speed $(\mathrm{rpm})$ & 3000 \\
Max Efficiency $(\%)$ & 95 \\
Mass $(\mathrm{kg})$ & 3 \\
Outer Diameter $\times$ Length $(\mathrm{mm} \times \mathrm{mm})$ & $166 \times 52$ \\
Max Operational Temp. $\left({ }^{\circ} \mathrm{C}\right)$ & 80 \\
Min Operational Temp. $\left({ }^{\circ} \mathrm{C}\right)$ & -40 \\
\hline
\end{tabular}

\subsection{Magnetic Harmonic Drives-Magdrives}

Another kind of magnetic gears can be obtained following a "Vernier motor" criteria similar to that of the conventional "Harmonic drives". We will call them "Magdrive" class, Figure 2. In fact the "harmonic drive" configuration was proposed by Chubb for a magnetic gear some years before the invention of the "Harmonic drive". Magdrives use a magnetic field wave whilst Harmonic drives use a mechanical deformation wave.

Figure 2. MAG SOAR Magdrive prototype. Max. torque $45 \mathrm{Nm}$.

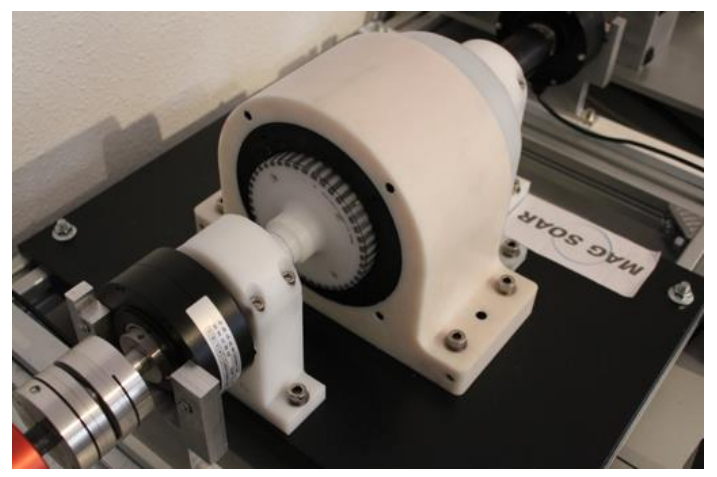


Magdrives are provided with a permanent magnet fixed to the input axle that generates a magnetic field wave. This magnetic field induces a magnetization in a set of soft magnetic teeth which tend to align with an outer set of permanent magnets (or outer teeth). If the outer teeth are earthed, then the soft magnetic intermediate teeth are fixed to the output axle although other kinematic inversions are possible as well. This configuration can presumably provide ratios up to 1:200.

Magdrives are suitable for cryogenic conditions. Particularly, a cryogenic Magdrive prototype, supported on non-contact superconducting bearings has been developed. Table 2 summarizes experimental results for the cyrogenic (Column 2) and other Magdrive.

Table 2. Comparison of experimental tests on Magdrive prototypes from MAG SOAR.

\begin{tabular}{lccc}
\hline Specification & \multicolumn{3}{c}{ MAGDRIVE } \\
\cline { 2 - 4 } & $\begin{array}{l}\text { Room Temp. } \\
\text { Prototype }\end{array}$ & Cryogenic Prototype & $\begin{array}{c}\text { MAG SOAR } \\
\text { MD-101 }\end{array}$ \\
\hline $\begin{array}{l}\text { Magneto-Mechanical } \\
\text { Combination }\end{array}$ & $\begin{array}{c}\text { Magnetic Teeth }+ \\
\text { Ball Bearing }\end{array}$ & $\begin{array}{c}\text { Magnetic Teeth }+ \\
\text { Superconducting } \\
\text { Magnetic Bearing }\end{array}$ & $\begin{array}{c}\text { Magnetic } \\
\text { Teeth + Dry } \\
\text { Lubricated }\end{array}$ \\
& Ball Bearing \\
\hline Reduction ratio (i) & 21 & 21 & 101 \\
Max output torque $(\mathrm{Nm})$ & 15 & 4 & 45 \\
Torque Density (kNm/m $\left.{ }^{3}\right)$ & 10.7 & 2.5 & 71 \\
Max input speed (rpm) & 500 & 3000 & 4500 \\
Max Efficiency $(\%)$ & 95 & - & 95 \\
Accuracy (arcmin) & \pm 3 & \pm 1 & \pm 0.1 \\
Mass (kg) & 5 & 8 & 2 \\
Envelope: Diameter $\times$ Length & $120 \times 110$ & $120 \times 400$ & $100 \times 80$ \\
(mm $\times$ mm) & 80 & -180 & +120 \\
Max. Operational Temp. $\left({ }^{\circ} \mathrm{C}\right)$ & -40 & -260 & -196 \\
Min Operational Temp. $\left({ }^{\circ} \mathrm{C}\right)$ & $>4$ millions & $>1.5$ millions & $>2$ millions \\
Input cycles lifetime & & &
\end{tabular}

A recent design developed by MAG SOAR achieves $71 \mathrm{kNm} / \mathrm{m}^{3}$ with a great reduction ratio, comparable to the PMG size 14 from Harmonic Drive Gmbh $\left(100 \mathrm{kNm} / \mathrm{m}^{3}\right)$ [9]. Efficiency is expected to be greater due to the lack of losses in the teeth contact. Temperature operational ranges are extremely wide, mainly due to the type of bearing used. The developments using superconducting magnetic bearing can handle extremely low temperature ranges close to the absolute zero.

The most outstanding properties of magnetic gears are derived from the torque/torsion behavior. It is radically different from that of the conventional gears. If we block the output axle of a gear and increase the torque in the input axle to try to move it we will make evident the difference between magnetic and mechanical gears. 
Magnetic gears will admit a shift angle in the input axle that increases linearly with the applied torque. Figure 3 shows experimental data of torque $v s$. shift angle for a 1:21 Magdrive (black dots). If we decrease the torque and change sign of it, the angle will follow the torque without any significant hysteresis. In this sense magnetic gears do have zero backlash. If we increase the torque up to its maximum value a non-linear dependence appears. If we try to increase the torque and overpass the limit, then the axle simply turns. For the magnetic gears nothing breaks down.

Figure 3. Experimental Torque vs. angle shift in MAGDRIVE Prototype (black dots) compared to a perfect mechanical gear (blue line).

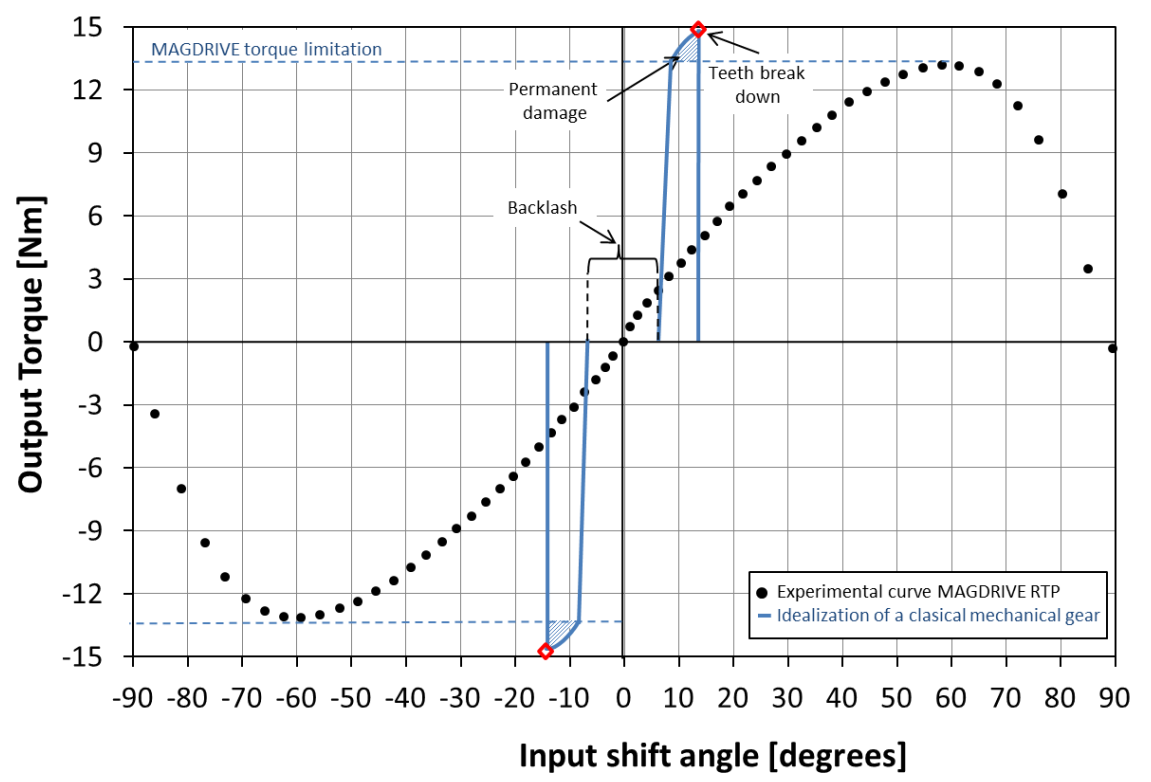

The case is quite different in conventional gears (blue line in Figure 3). A backlash is present due to the clearances needed for the movement. Therefore, if the movement is reversed there is a small but not negligible backlash around the origin. Once the gears are engaged, the input axle presents a rigid behavior with stiffness of the order of magnitude of the flexural stiffness of the teeth. Once the maximum admitted torque is reached a plastic deformation and fracture appears with permanent damage of the conventional gear.

The radically different behavior of magnetic and mechanical gears makes the meaning of "maximum admissible torque" to be quite distinct. For mechanical gears this means: "if you overpass that value you break the device". For magnetic gears this means: "it will transmit the movement up to that value of the torque, but if you try to overpass it will slide and nothing breaks down". The zero backlash properties are very desirable for the accurate control of the position in mechanism. Since these devices are torsionally more compliant, some specific considerations must be taken when controlling the position $[10,11]$.

\section{Magnetic Torque Limiters}

Other magnetomechanical devices that can be used for power transmission are magnetic torque limiters, Figure 4. They behave as 1:1 transmissions whenever the torque is under a limit. If the 
applied torque overpasses this limit they present an antijamming clutching effect that protects the output structure. Specific and optimized designs make these devices quite compact and competitive.

Figure 4. MAGSOAR TL-40 Magnetic Torque Limiter. Max. torque $40 \mathrm{Nm}$.

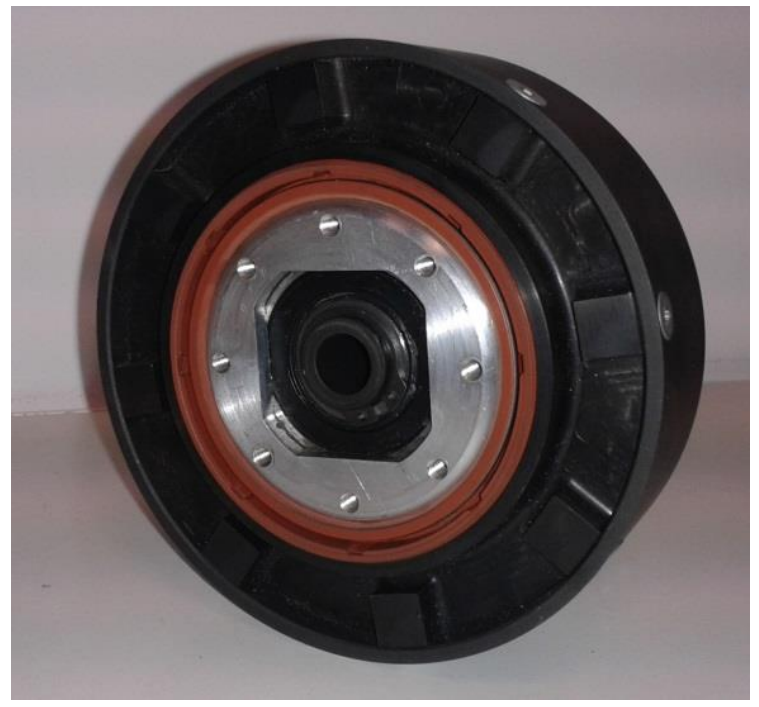

Additionally, magnetic torque limiters provide a certain degree of torsional elasticity that can be used to reduce the transmission of torsional vibrations. These magnetic torque limiters do not emit any kind of magnetic field around them. They do not dissipate any kind of power while engaging (applied torque below limit). While not engaging (applied torque over limit), a reduced dragging torque and heat release can be customized.

A main and unique feature of magnetic torque limiters is that they do not suffer wear or fatigue independently of the times they act limiting the torque.

Table 3 shows experimental data of a magnetic torque limiter from MAG SOAR.

Table 3. Magnetic torque limiter TL-45 manufactured by MAG SOAR SL performance.

\begin{tabular}{cc}
\hline Specification & MAGSOAR TL-40 \\
\hline Reduction ratio (i) & 1 \\
Max output torque $(\mathrm{Nm})$ & 40 \\
Torque Density $\left(\mathrm{kNm} / \mathrm{m}^{3}\right)$ & 106 \\
Max input speed $(\mathrm{rpm})$ & 15,000 \\
Max Efficiency $(\%)$ & 99.5 \\
Mass $(\mathrm{kg})$ & 2 \\
Envelope: Outer Diameter $\times$ Length $(\mathrm{mm} \times \mathrm{mm})$ & $112 \times 38$ \\
Max Operational Temp. $\left({ }^{\circ} \mathrm{C}\right)$ & 90 \\
Min Operational Temp. $\left({ }^{\circ} \mathrm{C}\right)$ & -55 \\
Operation hours & $>200 \mathrm{~h}$ \\
Torque limitations activations & $>300$ \\
\hline
\end{tabular}


Magnetic torque limiters torque capability is in the same order than conventional commercial ones (Ruflex KTR 012 TF torque limiter from 52 to $150 \mathrm{kN} / \mathrm{m}^{3}$ [12]). Moreover, their maximum speeds and efficiency are larger than those mechanical based on friction. There is not a severe degradation or failure when the torque limitation is activated. This is in contrast to conventional mechanical ones based in mechanical fusible or wear.

In order to use this kind of torque limiters in applications where the operational temperature range is wide like in aircrafts, it is essential to characterize the variation of the maximum transmissible torque against temperature. The variation of the maximum torque with respect to the temperature is shown in Figure 5. $\mathrm{NdFeB}$ magnetization varies with temperature and so this affects the torque transmission capability, the lower the temperature, the higher the magnetization and therefore the torque. The variation of the maximum torque is around $+12 \%$ in the lowest temperature tested and $-12 \%$ in the highest temperature with an almost linear variation with temperature.

Figure 5. Maximum torque vs. temperature.

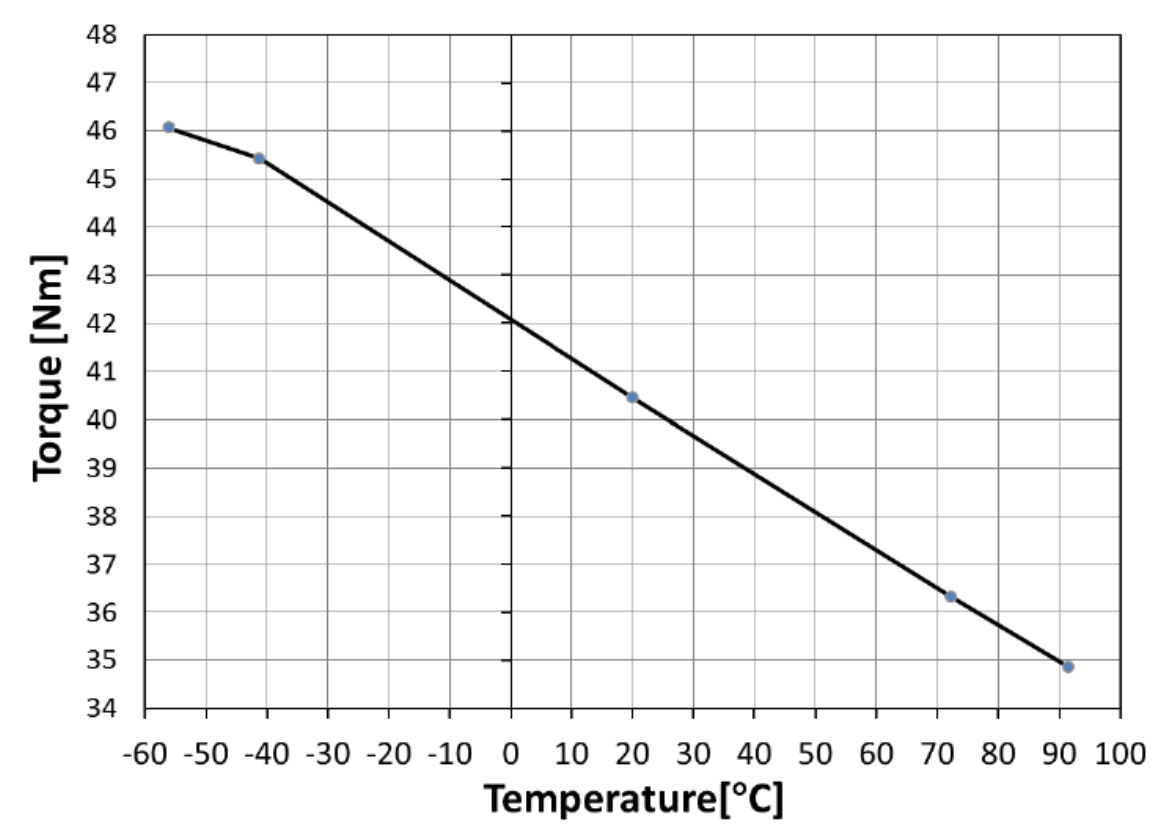

\section{Superconducting Magnetic Bearings}

Contactless bearings based in both permanent magnets and superconducting magnetic levitation are interesting to avoid all the tribological problems associated with contact at very low temperatures [3] such as friction, wear or energy losses [13-17]. In addition, insofar there is no contact between the moving parts, lubrication is not required. Superconducting Magnetic Bearings (SMBs) find application in many fields where lack of contact is a requirement or an advantage such as in flywheel systems and transportation [18], cryogenic turbine flow meters, cryocoolers and sensitive gyroscopes for space applications among other applications for cryogenic and space mechanisms [19-25]. Recently, it has been explored different shapes, sizes and combination of magnet-superconductor in order to obtain stable levitation positions [26-31]. There are some models that are useful to describe this interaction and that can be applied in finite elements programs as it is commonly used in mechanical engineering [32-34]. Some other parameters as the force relaxation or the rotation losses must be considered from the point 
of view of the mechanical engineer for an adequate design of the SMB [6,35,36]. Figure 6 presents the drawing plan and prototype of an axle using SMBs used for the cryogenic prototype of magnetic harmonic drive previously presented.

Figure 6. Mechanical drawing plan and prototype and of an axle supported by Superconducting Magnetic Bearings (SMBs).
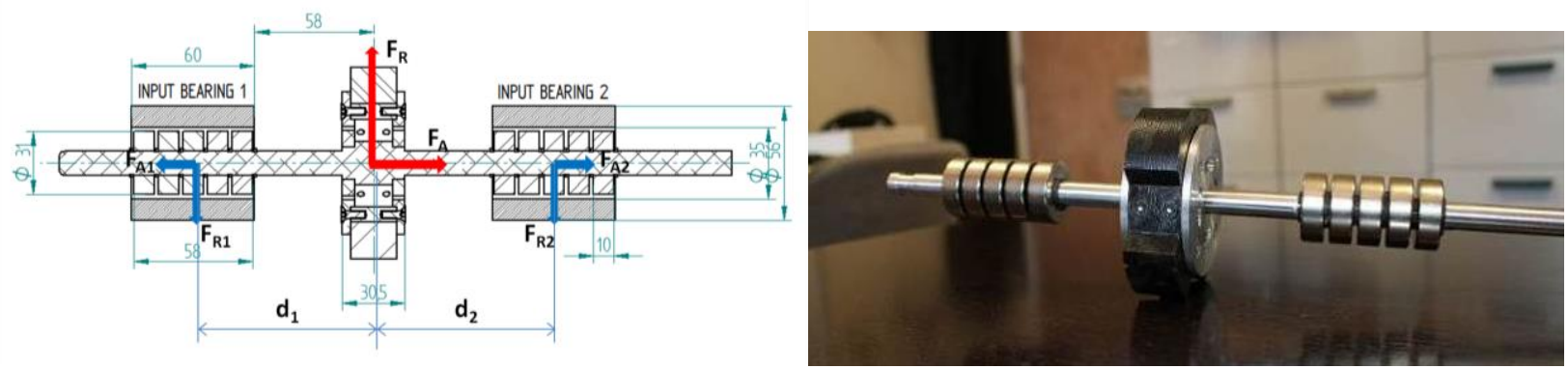

SMBs are designed considering $\mathrm{YBaCuO}$ as superconducting material and $\mathrm{NdFeB} \mathrm{N} 50$ as permanent magnet. The airgap between static and rotatory parts was $2 \mathrm{~mm}$. The final design of the SMB considered a safety factor of 2, which gave very large bearing elements (60 $\mathrm{mm}$ for input and $120 \mathrm{~mm}$ for output ones). In spite these SMBs have a large safety margin, SMBs, in general have much lower stiffness and load capacity than a mechanical ball bearing one. On the other hand, they do not have any friction or wear even at low temperature, and that was the reason for their selection.

Specifically MAG SOAR superconducting magnetic bearing have a performance shown in Table 4.

Table 4. Superconducting magnetic bearing performance.

\begin{tabular}{cc}
\hline Specification & $\begin{array}{c}\text { MAG SOAR } \\
\text { SMBs }\end{array}$ \\
\hline Axial maximum load $(\mathrm{N})$ & up to $1500 \mathrm{~N}$ \\
Axial stiffness $(\mathrm{N} / \mathrm{mm})$ & 150 \\
Radial stiffness $(\mathrm{N} / \mathrm{mm})$ & 50 \\
Maximum speed (rpm) & 25,000 \\
Efficiency $(\%)$ & 99.7 \\
Max Operational Temp. $\left({ }^{\circ} \mathrm{C}\right)$ & -190 \\
Min Operational Temp. $\left({ }^{\circ} \mathrm{C}\right)$ & -270 \\
Operation hours & $>1500 \mathrm{~h}$ \\
\hline
\end{tabular}

The maximum load capability and stiffness is much smaller than for a ball bearing conventional one. So it does the weight/load ratio. However, SMBs are very interesting for applications at cryogenic temperatures and ultrahigh speeds.

\section{Conclusions}

Magneto-mechanical transmission devices have several advantages over conventional mechanisms: no friction between rotatory elements (no power losses or heat generation by friction so increase of efficiency), no lubrication is needed (oil-free mechanisms and no lubrication auxiliary systems), reduced maintenance (no lubricant so no need of oil replacements), wider operational temperature 
ranges (no lubricant evaporation or freezing), overload protection (if overload occurs magnet simply slides but no teeth brake), through-wall connection (decoupling of thermal and electrical paths and environmental isolation), larger operative speeds (more efficient operative conditions), ultralow noise and vibrations (no contact no noise generation). In this work, we have presented three configurations of contactless mechanical components: magnetic gears, magnetic torque limiters and superconducting magnetic bearings:

Magnetic gears are able to produce reduction ratios from 2 to 125 by means of magnetic teeth in a single stage. They are reversible mechanisms: they can reduce but also multiply the velocity. They can also go clockwise or anticlockwise. Ratio, maximum torque, stiffness and damping can be customized. Axial or radial configuration can be built. Magnetic harmonic drives have been tested in very extreme conditions ( $-250{ }^{\circ} \mathrm{C}$ and $10^{-5}$ mbar) showing unique performance in terms of life and maximum speed.

Magnetic torque limiters provide a highly efficient torque transmission without contact between rotatory shafts. They prevent damage in machine and structural elements passively. When the torque is higher than the nominal, the magnetic torque limiters simply behave as a clutch. Wear, vibration and noise are drastically reduced. Misalignment of axles can be absorbed in magnetic torque limiters and throughwall transmission and protection is also available. Magnetic torque limiters have been tested at very high speeds and different temperatures.

Superconducting magnetic bearings have shown excellent stable behavior in machine with complex load conditions. SMB can hold both axial and radial loads, and the limit of the speed is 25,000 rpm. SMB reach higher stiffness and higher load capabilities thanks to an innovative manufacturing process of the superconductors and an optimized magnet configuration. Superconducting magnetic bearing can isolate vibrations from unbalanced rotatory parts.

We have reviewed the main characteristics and range of applications for each configuration. Temperature ranges, lifetime and maximum speeds provided by contactless mechanical components are larger than for the equivalent mechanical one.

\section{Acknowledgments}

The research leading to these results has received funding from the European Community's Seventh Framework Programme ([FP7/2007-2013]) under grant agreement $n^{\circ} 263014$ and $n^{\circ} 323423$.

\section{Author Contributions}

Jose Luis Perez-Diaz has been the project coordinator all the works related to the contactless components inside two FP7 projects MAGDRIVE and MAGBOX, additionally he has colaborated with MAG SOAR developing the high torque magnetic gears. Efren Diez-Jimenez has been the technical work coordinator of all the developments. Ignacio Valiente-Blanco has been responsable of the SMB developments and the high torque density magdrive optimization, Cristian Cristache was responsible of the mechanical and thermal design and he has also performed most of the tests, Marco-Antonio Alvarez-Valenzuela has been the responsible of manufacturing of the prototypes and Juan Sanchez-Garcia-Casarrubios has been in charge of all the electronic and auxiliary systems needed for testing the prototypes. 


\section{Conflicts of Interest}

The authors declare no conflict of interest.

\section{References}

1. Ostrovskaya, Y.L.; Yukhno, T.; Gamulya, G.; Vvedenskij, Y.V.; Kuleba, V. Low Temperature Tribology at the B. Verkin Institute for Low Temperature Physics \& Engineering (historical review). Tribol. Int. 2001, 34, 265-276.

2. Trautmann, A.; Siviour, C.R.; Walley, S.M.; Field, J.E. Lubrication of polycarbonate at cryogenic temperatures in the split Hopkinson pressure bar. Int. J. Impact Eng. 2005, 31, 523-544.

3. Theiler, G.; Gradt, T.; Klein, P. Friction and wear of PTFE composites at cryogenic temperatures. Tribol. Int. 2002, 35, 449-458.

4. Jian, L.; Chau, K.T. A Coaxial Magnetic Gear With Halbach Permanent-Magnet Arrays. IEEE Trans. Energy Convers. 2010, 25, 319-328.

5. Jørgensen, F.T.; Andersen, T.O.; Rasmussen, P.O. The Cycloid Permanent Magnetic Gear. IEEE Trans. Ind. Appl. 2008, 44, 1659-1665.

6. Valiente-Blanco, I.; Diez-Jimenez, E. Characterization and Improvement of Axial and Radial Stiffness of Contactless Thrust Superconducting Magnetic Bearings. Tribol. Lett. 2014, 54, 213-220.

7. Cristache, C.; Valiente-Blanco, I.; Diez-Jimenez, E.; Sanchez-Garcia-Casarrubios, A.J.; Perez-Diaz, J.L. Mechanical characterization of journal superconducting magnetic bearings: Stiffness, hysteresis and force relaxation. J. Phys. Conf. Ser. 2014, 507, doi:10.1088/17426596/507/3/032012.

8. Perez-Diaz, J.L. Superconducting Noncontact Device for Precision Positioning in Cryogenic Environments. IEEE ASME Trans. Mechatron. 2014, 19, 598-605.

9. Harmonic Drive AG Catalog. Available online: http://harmonicdrive.net/support/catalogs/ (accessed on 5 May 2014).

10. Misgeld, B.; Gerlach-Hahn, K. Control of Adjustable Compliant Actuators. Machines 2014, 2, 134-157.

11. Bouheraoua, M.; Wang, J.; Atallah, K. Influence of Control Structures and Load Parameters on Performance of a Pseudo Direct Drive. Machines 2014, 2, 158-175.

12. KTR Catalog. Available online: http://www.ktr.com/en/index/service/876_productcatalog/catalog/ productcatalog.htm (accessed on 5 May 2014).

13. Bassani, R. Magnetoelastic Stability of Magnetic Axial Bearings. Tribol. Lett. 2012, 49, 397-401.

14. Power Consumption. J. Tribol. 1996, 118, 839-846.

15. Di Puccio, F.; Bassani, R.; Ciulli, E.; Musolino, A.; Rizzo, R. Permanent magnet bearings: Analysis of plane and axisymmetric V-shaped element design. Prog. Electromagn. Res. M 2012, 26, 205-223.

16. Musolino, A.; Rizzo, R.; Tucci, M.; Matrosov, V.M. A New Passive Maglev System Based on Eddy Current Stabilization. IEEE Trans. Magn. 2009, 45, 984-987. 
17. Filion, G.; Ruel, J.; Dubois, M. Reduced-Friction Passive Magnetic Bearing: Innovative Design and Novel Characterization Technique. Machines 2013, 1, 98-115.

18. Werfel, F.N.; Floegel-Delor, U.; Rothfeld, R.; Riedel, T.; Goebel, B.; Wippich, D.; Schirrmeister, P. Superconductor bearings, flywheels and transportation. Supercond. Sci. Technol. 2012, 25, doi:10.1088/0953-2048/25/1/014007.

19. Navarro, R.; Elswijk, E.; Tromp, N.; Kragt, J.; Kroes, G.; Hanenburg, H.; de Haan, M.; Schuil, M.; Teuwen, M.; Janssen, H.; et al. Precision Mechanism for Optics in a Vacuum Cryogenic Environment. In Proceedings of International Conference on Space Optics, Rhodes, Greece, 4-8 October 2010; pp. 1-6.

20. Weisensel, G.N.; McMasters, O.D.; Chave, G.R. Cryogenic magnetostrictive transducers and devices for commercial, military, and space applications. Proc. SPIE 1998, 3326, 459-470.

21. Maillard, T.; Claeyssen, F.; LeLetty, R.; Sosnicki, O.; Pages, A.; Vazquez Carazo, A. Piezomechatronic-based systems in aircraft, space, and defense applications. Proc. SPIE 2009, 7331, 1-9.

22. Iizuka, T.; Maeda, Y.; Aihara, K.; Fujita, H. A micro X-Y- $\theta$ conveyor by superconducting magnetic levitation. In Proceedings of IEEE Symposium on Emerging Technologies and Factory Automation, Tokyo, Japan, 6-10 Novemver 1994; pp. 62-67.

23. Pérez-Díaz, J.L.; García-Prada, J.C.; Diez-Jimenez, E.; Valiente-Blanco, I.; Sander, B.; Timm, L.; Sánchez-García-Casarrubios, J.; Serrano, J.; Romera, F.; Argelaguet-Vilaseca, H.; et al. Non-contact linear slider for cryogenic environment. Mech. Mach. Theory 2012, 49, 308-314.

24. Serrano-tellez, J.; Romera-juarez, F.; González-de-maría, D.; Lamensans, M.; Argelaguet-Vilaseca, H.; Pérez-Díaz, J.L.; Sánchez-Casarrubios, J.; Díez-Jiménez, E.; Valiente-Blanco, I. Experience on a cryogenic linear mechanism based on superconducting levitation. Proc. SPIE 2012, 8450, doi:10.1117/12.925165.

25. Morales, W.; Fusaro, R.; Kascak, A. Permanent Magnetic Bearing for Spacecraft Applications. Tribol. Trans. 2003, 46, 460-464.

26. Valiente-Blanco, I.; Diez-Jimenez, E.; Perez-Diaz, J.L. Alignment effect between a magnet over a superconductor cylinder in the Meissner state. J. Appl. Phys. 2011, 109, doi:10.1063/1.3535548.

27. Diez-Jimenez, E.; Perez-Diaz, J.L. Foundations of Meissner Superconductor Magnet Mechanisms Engineering. In Superconductivity—Theory and Applications; Luiz, A.M., Ed; InTech: Rijeka, Croatia, 2011; pp. 153-172.

28. Diez-Jimenez, E.; Perez-Diaz, J.L. Flip effect in the orientation of a magnet levitating over a superconducting torus in the Meissner state. Phys. C Supercond. 2011, 471, 8-11.

29. Diez-Jimenez, E.; Sander, B. Tailoring of the flip effect in the orientation of a magnet levitating over a superconducting torus: Geometrical dependencies. Phys. C Supercond. 2011, 471, 229-232.

30. Perez-Diaz, J.L.; Diez-Jimenez, E.; Valiente-Blanco, I.; Herrero-de-Vicente, J. Stable thrust on a finite-sized magnet above a Meissner superconducting torus. J. Appl. Phys. 2013, 113, doi:10.1063/1.4792037.

31. Diez-Jimenez, E.; Valiente-Blanco, I.; Perez-Diaz, J.L. Superconducting Sphere and Finite-Size Permanent Magnet: Force, Torque, and Alignment Effect Calculation. J. Supercond. Novel Magn. 2012, 26, 71-75. 
32. Diez-Jimenez, E.; Perez-Diaz, J.L.; Garcia-Prada, J.C. Mechanical method for experimental determination of the first penetration field in high-temperature superconductors. IEEE Trans. Appl. Supercond. 2012, 22, doi:10.1109/TASC.2012.2208267.

33. Diez-Jimenez, E.; Perez-Diaz, J.L.; Castejon, C. FEM Algorithm for Solving Superconducting Meissner Repulsion Forces. Int. Rev. Mech. Eng. 2010, 4, 673-675.

34. Diez-Jimenez, E.; Perez-Diaz, J.L.; Garcia-Prada, J.C. Local model for magnet-superconductor mechanical interaction: Experimental verification. J. Appl. Phys. 2011, 109, doi:10.1063/1.3553581.

35. Qin, Y.; Hou, X. Influence of maglev force relaxation on the forces of bulk HTSC subjected to different lateral displacements above the NdFeB guideway. Phys. C Supercond. 2011, 471, 118-120.

36. Xia, Z.; Chen, Q.Y.; Ma, K.B.; McMichael, C.K.; Lamb, M.; Cooley, R.S.; Fowler, P.C.; $\mathrm{Chu}$, W.K. Design of superconducting magnetic bearings with high levitating force for flywheel energy storage systems. IEEE Trans. Appl. Supercond. 1995, 5, 622-625.

(C) 2014 by the authors; licensee MDPI, Basel, Switzerland. This article is an open access article distributed under the terms and conditions of the Creative Commons Attribution license (http://creativecommons.org/licenses/by/4.0/). 